\title{
On the HCCI octane boosting effects of $\gamma$-valerolactone
}

\author{
Author, co-author (Do NOT enter this information. It will be pulled from participant tab in \\ MyTechZone) \\ Affiliation (Do NOT enter this information. It will be pulled from participant tab in MyTechZone)
}

\begin{abstract}
This study examined the octane boosting effects of $\gamma$-valerolactone, a fuel derived from lignocellulosic biomass, under Homogeneous Charge Compression Ignition (HCCI) combustion mode. The experiments were performed in a Cooperative Fuel Research (CFR) engine under four sets of conditions defined by the combinations of intake temperatures and rotation speed. Octane boosting effects were rated with FACE (Fuel for Advanced Combustion Engine) $\mathrm{J}$ gasoline as a base fuel. Due to the non-miscibility of $\gamma$-valerolactone into FACE $\mathrm{J}$, a new approach was proposed in which the octane boosting effect of a mixture comprised up of two-third $\gamma$-valerolactone and one-third ethanol was investigated. To evaluate the effect of $\gamma$-valerolactone, the octane boosting effect of pure ethanol into FACE $J$ was also investigated such that comparison can be drawn. Further attempts were made to extract the octane boosting effects of pure $\gamma$-valerolactone. For convenience, both volumetric and molar approaches were considered to rationalize the experimental results. The results showed that $\gamma$-valerolactone is a good octane booster, and that it possesses higher octane enhancement potential than ethanol for a low volume fraction in FACE J. In contrary, opposite trends were observed for the higher volume fractions of $\gamma$-valerolactone. Finally, the assessment of the blending octane number for pure $\gamma$-valerolactone revealed nonlinear octane boosting effects.
\end{abstract}

\section{Introduction}

Global energy demands continue to grow as many developing counties are ensuring an access to the affordable, reliable and modern energy resources to their people for better quality life. As the energy portfolio stands today, petroleum-based fuels will remain the major sources of energy serving the human society for some decades to come. In transport sectors, the internal combustion engines (ICEs) are exclusively powered by burning fossil fuels. Over the years, there are growing concerns over the overwhelmingly depletion of petroleum reserves and increasing global warming. The $\mathrm{CO}_{2}$ emissions from burning fossil fuels is one of the main culprits of global warming [1].

Mitigating the impacts of environmental pollution and greenhouse gas emissions is a major challenge. One possible way to mitigate global warming is to shift from conventional fossil fuels to renewable fuels coming from sustainable resources. By 2050, renewables must represent at least $15-20 \%$ share to the total energy demand. To meet this target, the process technology for the conversion of lignocellulosic biomass into biofuels and chemicals with high process efficiency has to be continually developed over the upcoming years [2-4].

Page 1 of 17
Recently, $\gamma$-valerolactone (GVL) has attracted a considerable attention as a potential renewable fuel or as a fuel additive to petroleum-based fuels for various reasons [5-8]. $\gamma$-valerolactone can be derived from lignocellulosic biomass via several production routes, For instance it can be obtained by selective catalytic reduction of bio-derived levullinic acid (LA) [9,10]. A cost-effective way of producing bioderived LA in a large scale is still a bottleneck for the realization of $\gamma$ valerolactone as a renewable fuel. However, new catalyst design specifically targeting bio-renewable feedstocks conversion to $\gamma$ valerolactone is rapidly accelerating (see a recent report by Yan et al. [10]). With technological developments, $\gamma$-valerolactone production may soon be economically viable as a renewable fuel. Additionally, physical and chemical properties of $\gamma$-valerolactone make this molecule very attractive as potential future fuel [6]: i) it is liquid at normal conditions and has low melting point ( -31 oC $)$, high boiling point ( 208 oC), high density $(1.05 \mathrm{~g} / \mathrm{mL})$, and high fuel born oxygen $(32 \%)$, highly soluble in water $(100 \%)$ allowing biodegradation in case of leaks and spills. ii) It neither degrades with time nor forms peroxides with air. iii) It is non-toxic, safe to handle or store and transport globally in large quantities. iv) It has significantly low vapor pressure $(\sim 5$ Torr at $25 \circ$ oC) as compared to other oxygenates like methanol, ethanol and methyl tert-butyl ether. v) Unlike ethanol, $\gamma$-valerolactone does not form azeotrope with water which makes distillation process less energy demanding and cost effective for separating $\gamma$ valerolactone from water during the production of $\gamma$-valerolactone. vi) It has a comparable energy density $(29.7 \mathrm{MJ} / \mathrm{kg})$ and enthalpy of vaporization $(54.8 \mathrm{~kJ} / \mathrm{mol})$ as that of ethanol. vii) Few studies indicated that $\gamma$-valerolactone as a fuel additive has a notable effect of reducing soot and particulate matter emission [5,6]. Despite of the fact that $\gamma$ valerolactone offers an excellent platform as a potential biofuel to replace petroleum-based fuels, its application as a fuel or as fuel additive in ICEs has not been much explored.

Horváth et al. [6] pioneered the application of $\gamma$-valerolactone as a practical transportation fuel. In their study, $10 \% \gamma$-valerolactone and $10 \%$ absolute ethanol were blended in $90 \%$ by volume fraction of conventional gasoline (octane rating $=95$ ), respectively. Essentially, both blends were found to exhibit similar physical properties in addition to the motor octane numbers (MON 89.3), research octane number (RON 97.4) and blending RON of 105. While most of the data for $\gamma$-valerolactone were found comparable with ethanol, they concluded that $\gamma$-valerolactone makes an excellent candidate as a future fuel and/or fuel additive due to its lower vapor pressure. Recently, Bereczky et al. [5] studied the blending effects of $\gamma$ valerolactone on the combustion characteristics of a diesel fuel in a four cylinder, turbocharged direct injection diesel engine. While the authors found $100 \%$ diesel fuel showing the best engine performance, 
and the diesel blend $(76.9 \%$ diesel $+23.1 \%$ biodiesel $)$ delivered similar performance, $\gamma$-valerolactone -diesel blend $(71.4 \%$ fossil diesel + $21.5 \%$ biodiesel $+7.1 \% \gamma$-valerolactone) was reported to have a slightly lower performance in terms of power and fuel consumption. However, $\gamma$-valerolactone blended in diesel fuel was found to have significant effect on the reduction of carbon monoxide (CO), unburnt hydrocarbon (UHC) and soot. Bruycker et al. [7] has recently studied the pyrolysis of $\gamma$-valerolactone experimentally and computationally to provide the first detailed kinetic model. During pyrolysis, their results indicated that $\gamma$-valerolactone is mainly consumed by isomerization to 4-pentoic acid and hydrogen abstraction reactions. The likelihood of $\gamma$ valerolactone to form carboxylic acid is troublesome for environmental reasons. Under combustion, their potential presence in the exhaust of an engine requires further investigation.

The present trends in the development of more efficient modern spark ignition engines are moving towards increasing the compression ratio and implementing turbocharging [11]. To achieve high efficiency, fuels having high octane number are quite attractive to mitigate engine knocking events in SI engines. For this reason, $\gamma$-valerolactone (derived research octane number 110) might be a promising candidate as an octane booster when blended with gasoline like-fuel in an appropriate proportion in addition to its propensity to reduce harmful emissions. This study aims to examine the octane boosting potential of $\gamma$-valerolactone for its applicability as a fuel additive in internal combustion engines. The blending effects of $\gamma$-valerolactone is investigated by mixing it with a low octane fuel FACE $\mathrm{J}$ (octane number $\sim 70$ ). $0-20 \%$ of $\gamma$-valerolactone and half of $\gamma$-valerolactone volume fractions of ethanol were blended into FACE $\mathrm{J}$ to characterize the octane enhancement effects. Ethanol was added to enhance the miscibility of the mixtures. In addition, pure ethanol blended with FACE J was also studied to reliably extract the information about the octane boosting effect of pure $\gamma$-valerolactone.

\section{Experimental setup}

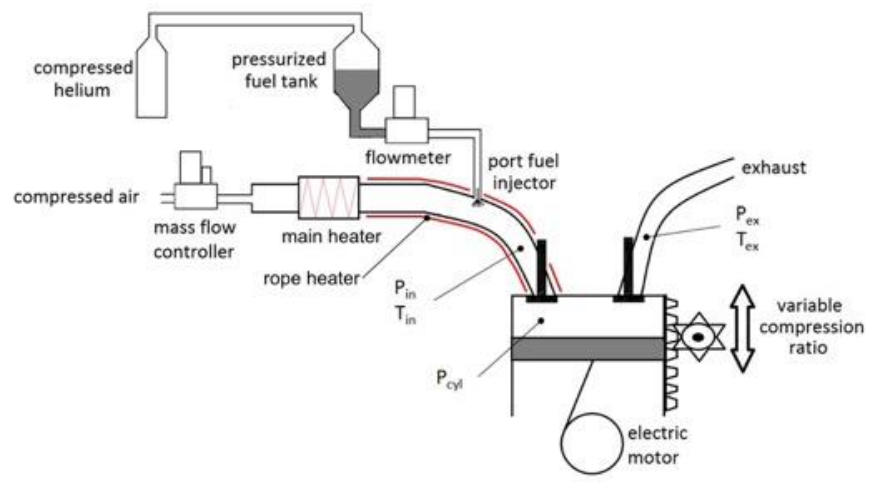

Figure 1. A schematic of the experimental setup.

Figure 1 shows a schematic representation of the experimental setup and Table 1 summarizes the main characteristics of the Waukesha F1/F2 Cooperative Fuel Research (CFR) engine used in this work. As the details of CFR set up can be found elsewhere [12], only a brief description is provided here. A usual CFR engine has a carburetor set upstream of the intake valve and operates under the spark ignition (SI) combustion strategy. For the present study, however, the intake manifold and the carburetor were replaced by a whole new intake manifold and a port fuel injector to enable the CFR engine operate under both SI and homogeneous charge compression ignition (HCCI) Page 2 of 17 combustion strategies. Additionally, the new intake manifold allows to achieve wider conditions of intake pressure ( 0.5 bar to 1.3 bar), intake temperature $\left(25^{\circ} \mathrm{C}\right.$ to $\left.200^{\circ} \mathrm{C}\right)$ and equivalence ratio $(\phi)$ or lambda $(\lambda)$ (from lean to slightly rich). The intake pressure was measured close to the intake valve of the engine, and the target intake pressure was regulated by adjusting the amount of intake air through a mass flow controller. The intake temperature was controlled by two heaters. The first heater served to warm up the main flow to the intake; whereas the second heater which was wrapped around the intake pipe helped to maintain a uniform temperature (see Figure 1). Finally, the equivalence ratio/lambda was computed with the help of a mass flowmeter set placed between the fuel tank and the port fuel injector and was controlled by adjusting the pulse width of the port fuel injector.

Table 1. Characteristics of the CFR engine.

\begin{tabular}{lll}
\hline \hline Parameter & Unit & Value \\
\hline \hline Displaced volume & $\mathrm{cc}$ & 611.7 \\
Stroke & $\mathrm{mm}$ & 114.3 \\
Bore & $\mathrm{mm}$ & 82.55 \\
Connecting rod & $\mathrm{mm}$ & 256 \\
Compression ratio & - & $4: 1$ to $18: 1$ \\
Number of valves & - & 2 \\
Exhaust valve opening & $\mathrm{CA}$ ATDC & 140 \\
Exhaust valve closure & $\mathrm{CA}$ ATDC & -345 \\
Inlet valve opening & $\mathrm{CA}$ ATDC & -350 \\
Inlet valve closure & $\mathrm{CA}$ ATDC & -146 \\
Coolant water temperature & ${ }^{\circ} \mathrm{C}$ & $100 \pm 1.5$ \\
Oil temperature & ${ }^{\circ} \mathrm{C}$ & $57 \pm 8$ \\
\hline \hline
\end{tabular}

Combustion behavior of the fuel blends (see fuel matrix in Table 2) were investigated by capturing the signals from pressure transducers and thermocouples. The in-cylinder pressure was monitored through an AVL QC34D piezo-electric pressure transducer instead of the standard detonation pickup. In addition, two AVL LP11DA absolute pressure transducers were employed to record the intake pressure and the exhaust pressure. All these measurements were recorded with a resolution of 0.2 crank angle (CA) with the help of an AVL 365C encoder. Besides pressures measurements, two K-type thermocouples were installed to monitor the temperatures of the intake and the exhaust. Finally, data were acquired for a total of 200 consecutive cycles and post-processed with the help of a typical thermodynamic analysis. The details of the data post-processing can be found elsewhere [12].

\section{Fuel matrix}

As stated earlier, this study aims to examine the impact of $\gamma$ valerolactone on the autoignition behavior of low octane base fuel under HCCI combustion mode. A single low-octane number Fuel for Advanced Combustion Engine (FACE), known as FACE J (RON = 70.7 and $\mathrm{MON}=68.8$ ) [13], was employed as a base fuel. Unfortunately, the miscibility of $\gamma$-valerolactone into FACE $\mathrm{J}$ is limited to a very small fraction. Therefore, ethanol was added to allow miscibility. Table 2 below lists some properties of these fuels. 


\begin{tabular}{cccc}
\hline \hline Fuel & FACE J & Ethanol & $\gamma$-Valerolactone \\
\hline \hline RON & 73.8 & 109 & $130[14]$ \\
MON & 70.1 & 90 & - \\
$\mathrm{S}=(\mathrm{RON}-\mathrm{MON})$ & 3.7 & 19 & - \\
Density $[\mathrm{g} / \mathrm{L}]$ & 742 & 789 & 1050 \\
Molar mass $[\mathrm{g} / \mathrm{mol}]$ & 101.7 & 46.07 & 100.12 \\
Flash point $\left({ }^{\circ} \mathrm{C}\right)$ & & $13[15]$ & $96.1[15]$ \\
Boiling point $\left({ }^{\circ} \mathrm{C}\right)$ & & $78[15]$ & $207[15]$ \\
Melting point $\left({ }^{\circ} \mathrm{C}\right)$ & & $-114[15]$ & $-31[15]$ \\
$\Delta_{\text {vap }} H^{\circ}(\mathrm{kJ} / \mathrm{mol})$ & & $42.6[15]$ & $54.8[15]$ \\
$\Delta_{\mathrm{c}} H^{\circ}$ liquid $(\mathrm{kJ} / \mathrm{mol})$ & & $-1367.6[15]$ & $-2649.6[15]$ \\
\hline \hline
\end{tabular}

$\gamma$-valerolactone was blended into FACE J on a volume-basis. As stated above, ethanol was added to enhance miscibility. Note that each mixture has ethanol to $\gamma$-valerolactone volume ratio of $1: 2$, and rest is made up by FACE J. To examine the boosting effect of $\gamma$ valerolactone, pure ethanol blended into FACE J was also investigated. Table 3 lists the fuel matrices prepared for this investigation.

Table 3. Fuels matrix based on a volume-basis.

\begin{tabular}{ccc}
\hline \hline $\begin{array}{c}\text { FACE J } \\
\text { \%vol }]\end{array}$ & $\begin{array}{c}\text { Ethanol } \\
{[\% \text { vol }]}\end{array}$ & $\begin{array}{c}\gamma \text {-Valerolactone } \\
{[\% \text { vol }]}\end{array}$ \\
\hline \hline 100 & - & - \\
92.5 & 2.5 & 5 \\
88.75 & 3.75 & 7.5 \\
85 & 5 & 10 \\
70 & 10 & 20 \\
95 & 5 & - \\
92.5 & 7.5 & - \\
90 & 10 & - \\
85 & 15 & - \\
80 & 20 & - \\
\hline \hline
\end{tabular}

\section{Methodology}

It is worthwhile to detail our approaches of rating an octane number of a given fuel in a CFR engine. Octane boosting effects of $\gamma$ valerolactone is rated on the basis of four HCCI octane numbers. These HCCI octane numbers are based on the combination of intake temperature and rotation speed from RON $\left(600 \mathrm{rpm}\right.$ and $\left.52{ }^{\circ} \mathrm{C}\right)$ and MON (900 rpm and $149^{\circ} \mathrm{C}$ ) tests. Other parameters such as intake pressure and lambda $(\lambda)$ are set fixed at 1.0 bar and $3(\phi=0.333)$, respectively. Those HCCI octane numbers were used to rate sample fuels under multiple conditions and finally to assess the individual or combined impact of the intake temperature and the rotation speed. Figure 2 maps out all four HCCI octane numbers corresponding to intake temperatures and rotation speeds. The color code in Figure 2 identifies a given HCCI octane number, and this definition is kept throughout the paper.

Page 3 of 17

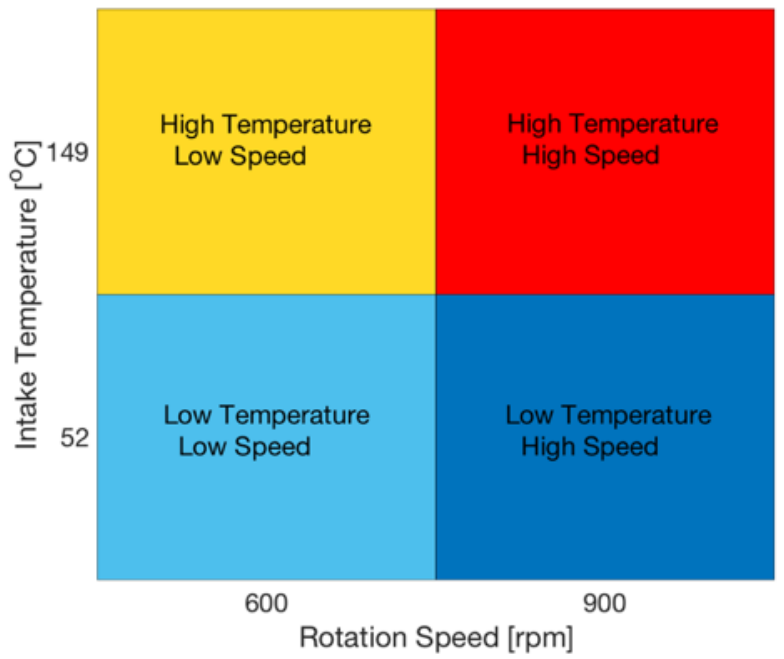

Figure 2. HCCI octane numbers map with respect to the intake temperature and the rotation speed.

With all the four set of conditions defined, yet reference scales are required to rate the octane numbers of the sample fuels. Various mixtures of Primary Reference Fuels (PRFs), binary mixture of nheptane and isooctane, were investigated to build the octane number scales. Here, octane number of PRFs reflects the volumetric fraction of isooctane in the mixture. Under HCCI combustion mode, the definition of the octane scale differs from that of RON or MON. The knock intensity criterion, which rates the octane number by reaching a certain compression ratio, is replaced by a combustion phasing criterion. By sweeping the compression ratio for a certain fuel, combustion phasing may vary from a late combustion (well after top dead center) to an early combustion (before top dead center). In this study, the combustion phasing criterion is picked at 3 crank angles after top dead center (CA ATDC), and the corresponding compression ratio translates into the octane number. Unfortunately, even if HCCI combustion was adequately stable, it was difficult to obtain a specific combustion phasing. Therefore, a sweep of the compression ratio was performed, and the specific combustion phasing is located by interpolation - an example of such approach is illustrated in Figure 3 for PRF60. 


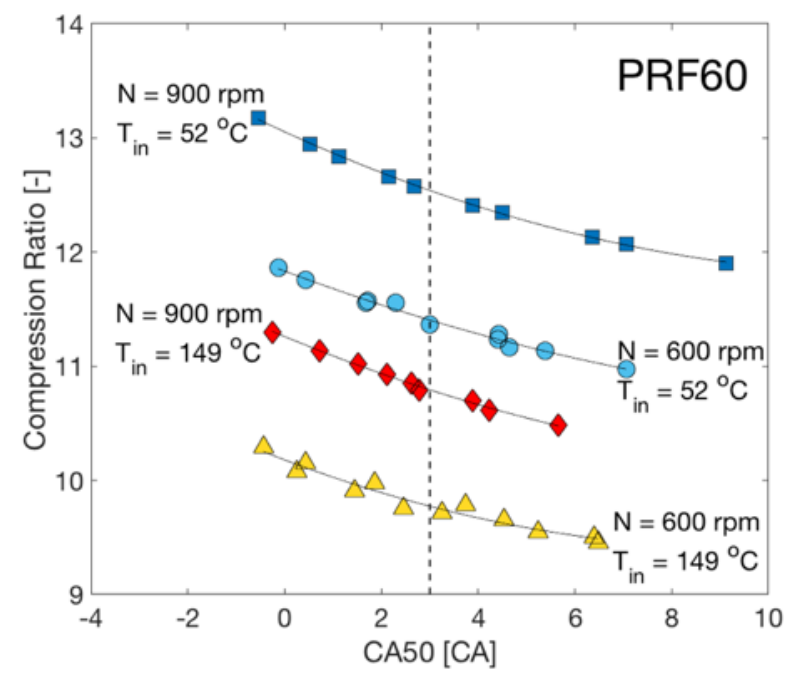

Figure 3. Compression ratio versus CA50 for PRF60 fuel under the four set of HCCI conditions. Vertical dashed line corresponds to the combustion phasing criterion.

The approach described above was also employed for all reference fuels (PRF60 to PRF100 with a step size of 10 in octane number). All these reference fuels displayed similar behavior as that shown in Figure 3 for PRF60 (see Appendix 1). Finally, calibration curves as illustrated in Figure 4 were established. A data point for the compression ratio corresponding to a $3 \mathrm{CA}$ ATDC for each given reference fuel was read which eventually translated into an octane number versus compression ratio chart providing the octane scales for each HCCI octane number (see Figure 4). The observed trends for each HCCI octane number were fitted through second-order polynomials which was used to readily obtain the octane number of a fuel under investigation. The coefficients of the second-order polynomials are provided in Appendix 1. From Figure 4, few observations could be made. Expectedly, compression ratio is found to increase with increasing the octane number of a fuel provided that the combustion phasing is kept constant. Moreover, it was found that the compression ratio is increased when the rotation speed is moved up from $600 \mathrm{rpm}$ to $900 \mathrm{rpm}$ for a given intake temperature. Similar observation was made by Aroonsrisopon et al. [16]. However, an opposite trend is observed when intake temperature moves from low to high for a given rotation speed (see Dubreuil et al. [17] for similar observation). A meaningful trend is observed by properly reflecting the individual effect of the rotation speed and the intake temperature e.g., low rotation speed and high temperature requires the least compression ratio to acquire the same combustion phasing as opposed to other combinations of HCCI conditions for a given fuel; whereas the high rotation speed and low intake temperature condition effected into the highest compression ratio as expected. Interestingly, the low temperature and low speed data almost overlap with that of the high temperature and high speed revealing that the opposite effect of intake temperature and the rotation speed to the compression ratio almost nullifies each other. Again, these observations resonate well with an earlier report by Waqas et al. [18] despite the authors had a higher compression ratio range pertinent to the slightly different experimental approach.

Page 4 of 17

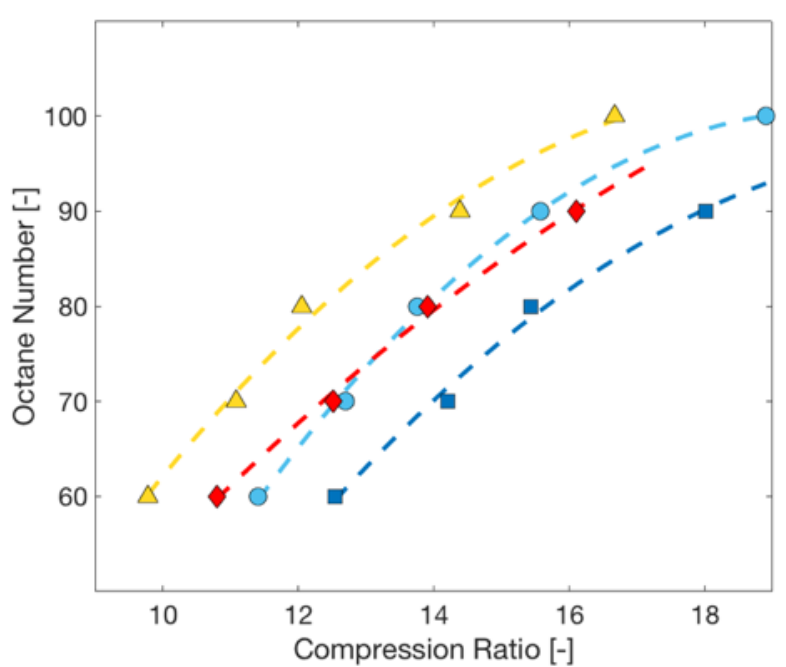

Figure 4. A plot showing octane number scales for four HCCI octane numbers. Symbols indicate the measured data points; whereas the dashed lines are the results of the fit to the second-order polynomial.

\section{Experimental results}

The octane number scales as illustrated in Figure 4 were utilized to determine the octane number of each fuel matrices listed in Table 3 under the four HCCI octane numbers. The results are presented below in their respective sections. The first and the second sections will focus on the results for a mixture of $2 / 3 \gamma$-valerolactone and $1 / 3$ ethanol into FACE J gasoline and the results for pure ethanol into FACE J gasoline, respectively, and those results will be discussed accordingly in the sections to follow. The results are presented with both the rated octane numbers, directly assessed from the octane number scales (Figure 4), and the blending octane number computed from the following equation taken from RON, MON or AKI blending studies [19].

$$
O N_{\text {blend }}=\left(1-C_{\text {booster }}\right) O N_{\text {base }}+C_{\text {booster }} \text { OON }_{v, \text { booster }}
$$

Where, the terms used are the measured octane number of the blend $\left(O N_{\text {blend }}\right)$, the octane number of the based-fuel $\left(O N_{\text {base }}\right)$ and the volume fraction of booster $\left(C_{\text {booster }}\right)$. In equation 1 , all the parameters are determined experimentally to eventually extract the volumetric blending octane number $\left(\right.$ bON $_{v}$,booster $)$.

Equation 1 considers a linear blending relationship on a volume-basis between the base fuel and the booster. However, non-linear blending effects are reported in the literature showing a huge dependency on the volume fraction of the octane booster [19-23]. From a petroleum perspective, the volume approach is often a choice for rating the octane boosting effects. However, from an engine perspective, a molar approach may be a better choice. Besides, the molar-basis approach is reported to yield a better description of the linear blending relationship as opposed to the volume-basis approach $[19,24]$. Hence, our results are also analyzed based on the following Equation 2 which is the modified version of Equation 1 on a molar-approach.

$$
O N_{\text {blend }}=\left(1-x_{\text {booster }}\right) O N_{\text {base }}+x_{\text {booster }} \text { OON }_{m, \text { booster }}
$$

In Equation 2, $x_{\text {booster }}$ corresponds to the mole fraction of the booster in the fuel blend and is expressed according to Equation 3 and Equation 
4. The rest terminologies are the same as the volume-basis except that the molar blending octane number $\left(b O N_{m, b o o s t e r}\right)$ will be computed here.

$$
\begin{gathered}
x_{\text {booster }}=\frac{C_{\text {booster }}}{C_{\text {booster }}+\left(1-C_{\text {booster }}\right) r_{m v}} \\
\boldsymbol{r}_{\boldsymbol{m} v}=\frac{\boldsymbol{v}_{\text {booster }}}{\boldsymbol{v}_{\text {based }}}=\frac{\frac{\boldsymbol{M}_{\text {booster }}}{\boldsymbol{\rho}_{\text {booster }}}}{\frac{\boldsymbol{M}_{\text {based }}}{\boldsymbol{\rho}_{\text {based }}}}
\end{gathered}
$$

\section{Octane boosting effects of a $\gamma$-valerolactone - ethanol mixture}

\section{Volume-basis approach}

Appendix 2 compiles the experimental results for pure FACE J; whereas Appendix 3 provides the results for various fuel blends with volume fraction of two third $\gamma$-valerolactone and one third ethanol mixture. Using these results and the octane numbers scales provided in Figure 4, the octane numbers of each fuel blends were extracted for all four HCCI conditions. The results are shown in Figure 5. As can be seen, the HCCI octane rating do not match with the standard RON and MON of the fuel. For example, the octane numbers of FACE $J$ are found to be 70 and 74 for HCCI conditions corresponding to RON and MON ones, respectively, which are quite different from the values listed in Table 2. Such results are not surprising considering the fact that HCCI octane numbers are purely chemistry-governed while the actual RON and MON of a fuel depends both on chemistry and flame propagation, and that the criterion to assess these numbers is different (HCCI is based on a threshold phasing while RON and MON are based on a specific knock intensity). Trends in Figure 5 show that the octane number monotonically increases with the increase of the volume fraction of the booster $(2 / 3 \gamma$-valerolactone $+1 / 3$ ethanol) for all HCCI conditions. This enhancement of octane number highlights the octane boosting potential of such a mixture. Decoupling the different conditions used, two major trends can be observed with respect to the intake temperatures only. At low intake temperature $\left(52{ }^{\circ} \mathrm{C}\right)$, the first addition of the $\gamma$-valerolactone - ethanol mixture sharply enhances the octane number of the fuel blend. Then, the octane number continues to increase nearly linearly at $900 \mathrm{rpm}$ while at $600 \mathrm{rpm}$, an intermediate slower raise was observed. In contrary, at high temperature $\left(149^{\circ} \mathrm{C}\right)$, the octane number was found to increase almost linearly regardless of the rotation speed. An exception occurred for $30 \%$ by volume of the booster $(2 / 3 \gamma$-valerolactone $+1 / 3$ ethanol) where the rated octane numbers slightly differ. These observations may allow us to conclude that the octane enhancement effects for the mixture of $\gamma$-valerolactone and ethanol is non-linear for low intake temperature; whereas the trend show almost-linear effects for high intake temperature. Nevertheless, some caution is warranted in our conclusion as the octane number of the booster used here is unknown. By knowing the octane number of the booster, the data presented in Figure 5 may be used to readily identify the non-linear effects if any such trend exists. For meaningful conclusions, the computation of the blending octane numbers is crucial.

Page 5 of 17

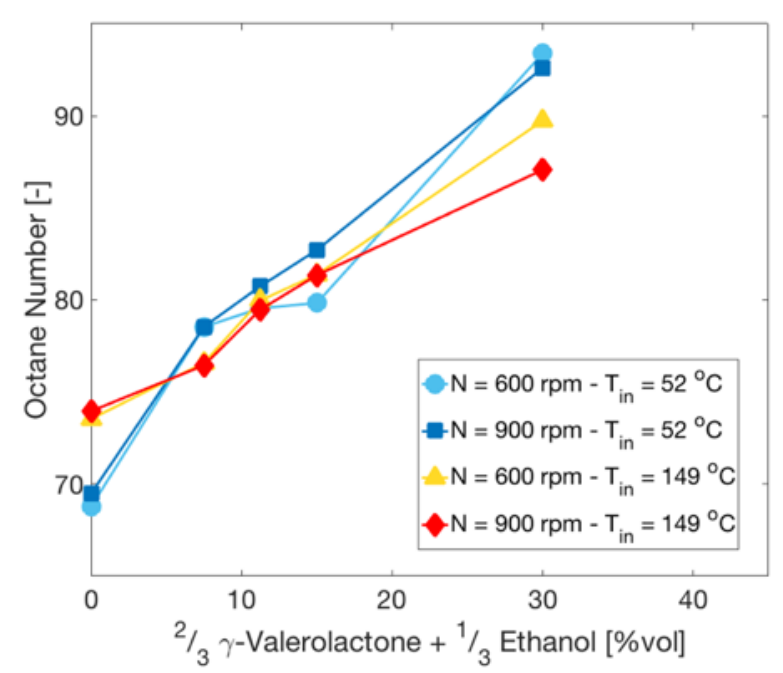

Figure 5. Octane number rating for various volumetric fraction of $\gamma$ valerolactone - ethanol mixture.

The results presented in Figure 5 are used to assess the blending octane number by employing Equation 1. For this assessment, the octane number of the base fuel (FACE J) for each set of conditions was also determined in this study. Finally, the blending octane numbers were computed which are shown in Figure 6. Blending octane numbers were found to range from 100 to 200 . Clearly, two distinct trends can be observed for each intake temperatures. While the low intake temperature resulted into a decreasing trend for the blending octane number, the high intake temperature showed an opposite trend, and finally they showed a convergence on the finite blending octane numbers. As variable blending octane numbers were observed to be independent of the HCCI conditions, one can conclude that the $\gamma$ valerolactone - ethanol mixtures exhibit non-linear octane boosting effects. Furthermore, two kinds of non-linear octane boosting effect can be observed namely synergistic and antagonistic effects. By definition, synergistic non-linear blending effects occurs when the derived blending octane number is greater than the octane number of the booster, and the opposite is true for antagonistic non-linear blending effects. Here, no distinction for the non-linear effects can be made as the octane numbers of the $\gamma$-valerolactone - ethanol mixture are unknown under the conditions studied here. Nonetheless, the decreasing and increasing trends for the low and high intake temperatures, respectively, finally converging on the finite values may allow us to estimate the octane number of the booster blend. This would then mean that the fuel blends (low volume fraction of the booster) show a significant synergistic non-linear blending effects at low intake temperature; whereas antagonistic effects are observed for low concentrations of the booster at high intake temperature which may eventually switch into synergistic effects at the intermediate volume fraction of the booster (see Figure 6). 


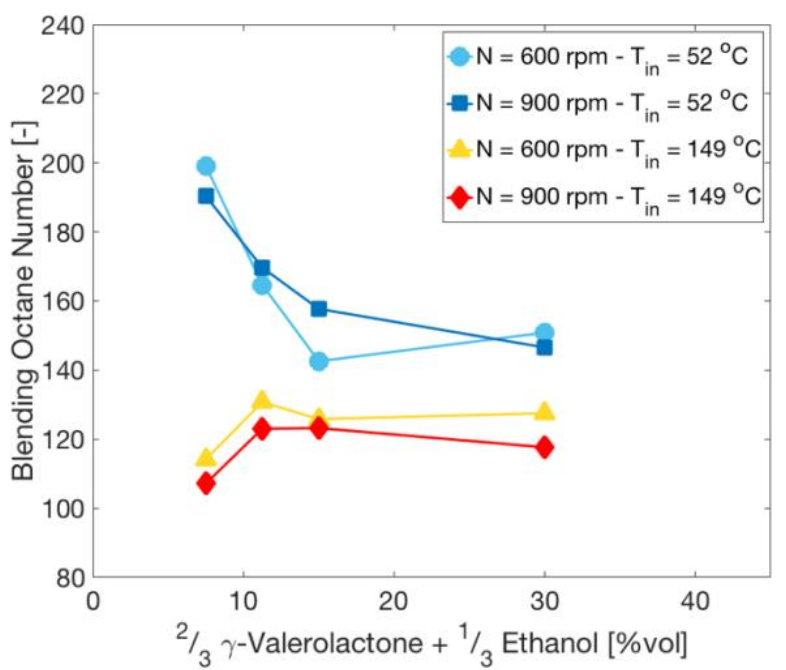

Figure 6. Blending octane number for various volumetric fraction of $\gamma$-valerolactone - ethanol mixture.

\section{Molar-basis approach}

Another way to investigate the octane boosting effects of an octane improver, or a mixture of octane improver as it is the case here, is to perform the same approach as described in the previous section, but on a molar-basis instead. As discussed earlier, such an approach is useful to rationalize the non-linear boosting effects of an octane improver. The molar basis data were derived by using equations 2 to 4 with the results displayed in Figure 5. Note that the two third $\gamma$-valerolactone one third ethanol blend by volume now translates into $55 \%$ of $\gamma$ valerolactone and $45 \%$ of ethanol by mole fraction. For computations, the molar mass $\left(M_{\text {booster }}\right)$ and the density $\left(\rho_{\text {booster }}\right)$ of the blend were taken as $75.82 \mathrm{~g} / \mathrm{mol}$ and $963 \mathrm{~g} / \mathrm{L}$, respectively. Figure 7 shows the derived octane numbers as a function of the molar fraction of the octane booster. Similar trends to that seen in volume-basis approach were observed for the molar-basis of this particular octane booster. Nonetheless, smoother trends could be noticed in this approach. That being said, the molar-basis does not necessarily suppress the nonlinearity of the octane boosting effect rather this approach forces to the lower values of the blending octane numbers for a given condition. A better picture of this change would have been possible by knowing the octane number of the booster. In both approaches, the observed trends are almost identical. Somewhat, the molar-basis results show closer to the linear trend such that less effects can be expected.

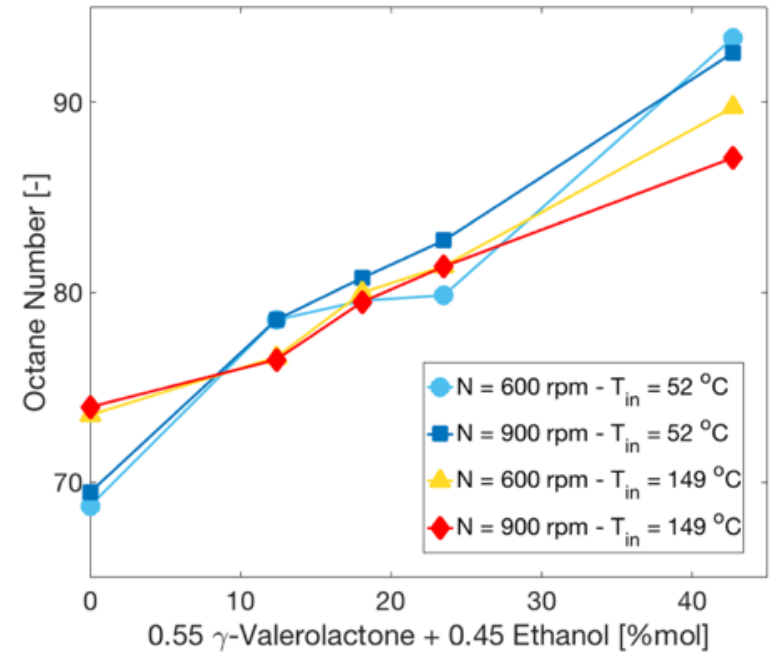

Figure 7. Octane number for various molar fraction of $\gamma$ valerolactone - ethanol mixture.

Finally, the blending octane numbers on the molar-basis were also computed and the results are shown in Figure 8. Again, the similar conclusions can be drawn, i.e. the fuel blends exhibit synergistic nonlinear blending effects at low intake temperature and antagonistic nonlinear blending effects at high temperature. Here, one notable difference is the narrower range of the blending octane number 90 $150)$ as opposed to the range observed in volume-basis approach $(100$ -200). This narrower range hints to the lesser boosting effect induced by the molar-basis approach. Moreover, as lower effects are seen for molar-basis approach, the finite value at which the curves converge is probably closer to octane number of the booster. Therefore, the octane number of the $\gamma$-valerolactone and ethanol blend can be estimated to be $\sim 125$ at low intake temperature and close to 110 at high intake temperature regardless of the rotation speed.

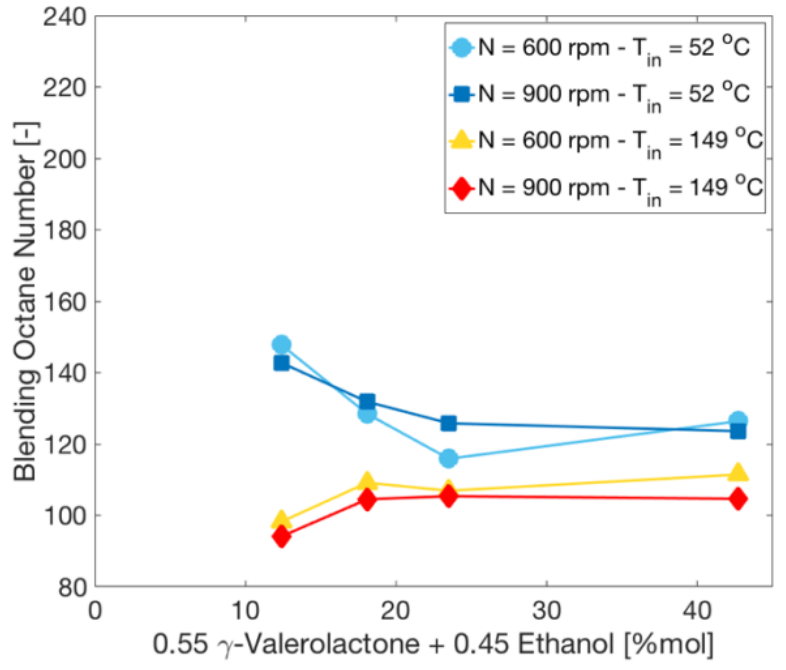

Figure 8. Blending octane number for various molar fraction of $\gamma$ valerolactone - ethanol mixture.

Page 6 of 17 


\section{Octane boosting effects of ethanol}

The lack of miscibility of $\gamma$-valerolactone in FACE J warrant a third fuel to be used as a solvent. Ethanol was selected for this purpose. The drawback of doing so is that the octane boosting effects of pure $\gamma$ valerolactone will be masked and could not be easily determined. However, an attempt was made to extract the information about the octane boosting of $\gamma$-valerolactone by conducting additional experiments by blending ethanol in FACE J. The approach adopted here is identical to that described in the previous section. The results are discussed below.

\section{Volume-basis approach}

Appendix 4 compiles the experimental results of ethanol and FACE J blends. The derived octane numbers of the FACE J and ethanol blends are shown in Figure 9. As can be seen, the rated octane numbers rapidly increase with the increase of the ethanol volume fraction. The effect is seen more pronounced for the low intake temperature as compared to the high intake temperature. Moreover, the trends observed at low intake temperatures clearly show the non-linear blending effects of ethanol with more impact originating from the high rotation speed. Nonetheless, the final octane number is almost identical for the low intake temperatures and highest volume fraction of ethanol. At high intake temperatures, the octane numbers for both rotation speed are almost identical showing some linear increase with ethanol volume, but the trends soon deviate showing more pronounced non-linear octane boosting effects for high rotation speed (see Figure 9). As stated previously, there are no final octane values for ethanol that can be used to justify non-linear blending effects. So, the evaluation of the blending octane numbers may provide useful information.

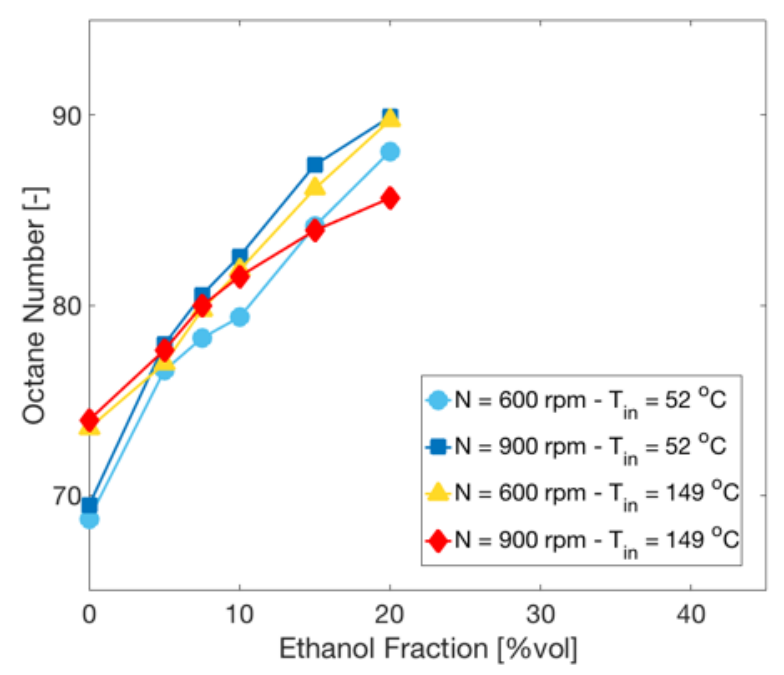

Figure 9. Octane number for various volumetric fraction of ethanol.

As discussed in earlier sections, the blending octane numbers were evaluated and the results are displayed in Figure 10. As can be seen, the non-linear blending effects are significant with ethanol as a booster. The data at low intake temperature strictly show synergistic non-linear effects. At high temperatures, both the synergistic and antagonistic non-linear effects could be observed. Particularly, the data obtained at the high rotation speed and high intake temperature show an interesting trend. Initially, the blending octane increases with the increment of ethanol volume fraction. Further increase of the ethanol

Page 7 of 17 volume fraction caused the blending octane number to monotonically drop showing synergistic non-linear blending effects. The blending octane number for the high intake temperature and low rotation speed plateaued at $\sim 155$ with the increase of ethanol volume fraction (see Figure 10).

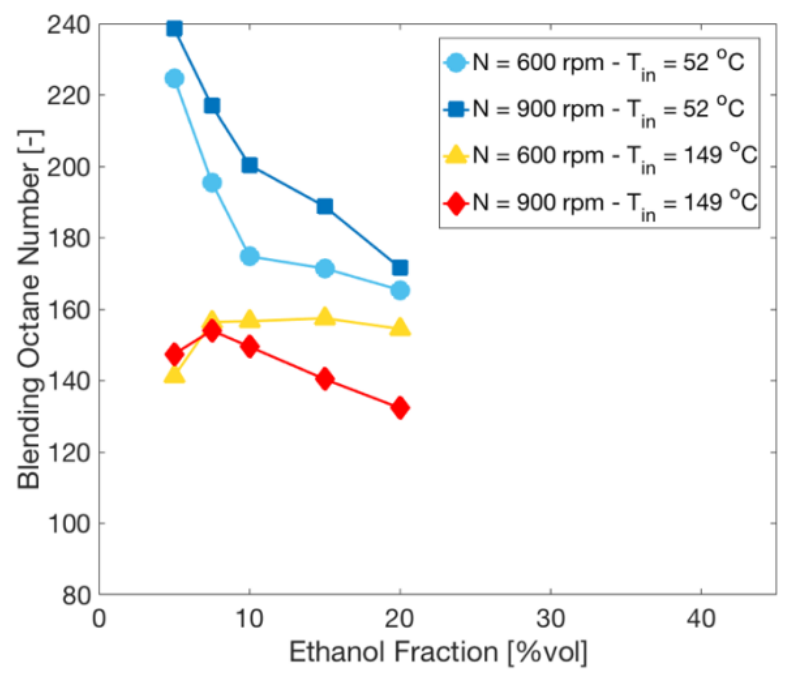

Figure 10. Blending octane number for various volumetric fraction of ethanol.

\section{Molar-basis approach}

The volume-basis approach led to some useful conclusions above. However, the molar-basis approach may be more useful to further illustrate the non-linearity boosting effects of ethanol. By employing Equations 3 and 4, the results presented in Figure 9 can easily be transferred to the results displayed in Figure 11. Again, molar-basis approach did not alter the trend observed earlier. However, the molarbasis forces the non-linear boosting effects to be less pronounced with the increase of the ethanol mole fractions.

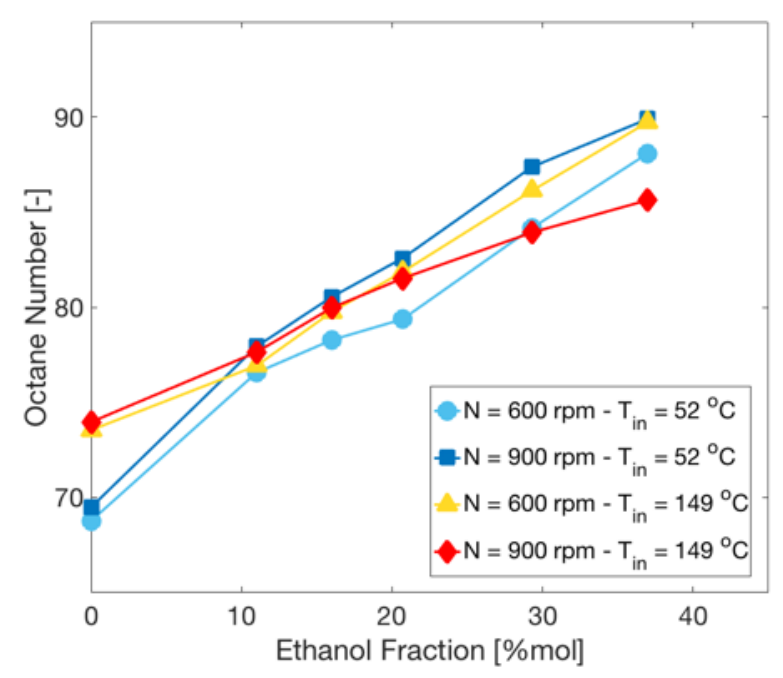

Figure 11. Octane number for various molar fraction of ethanol. 
Figure 12 displayed the evaluated blending octane numbers for various mole fraction of ethanol. As can be seen, none of the curves asymptote to a certain value enabling to estimate the non-linear blending octane boosting of pure ethanol. The data obtained at low intake temperature showed pronounced non-linear synergistic effects for both rotation speeds. At high intake temperature and high rotation speed, discernible non-linear synergistic blending effects were observed. In contrast, the high temperature and low rotation speed showed purely antagonistic blending effects (see Figure 12) providing an asymptote value of $\sim 120$. As in the previous section, the blending octane number of the ethanol is estimated to be between 120 and 125 for low intake temperature regardless of the rotation speed. As for high temperature and high rotation speed, the blending octane number will attain a value of 105 or less.

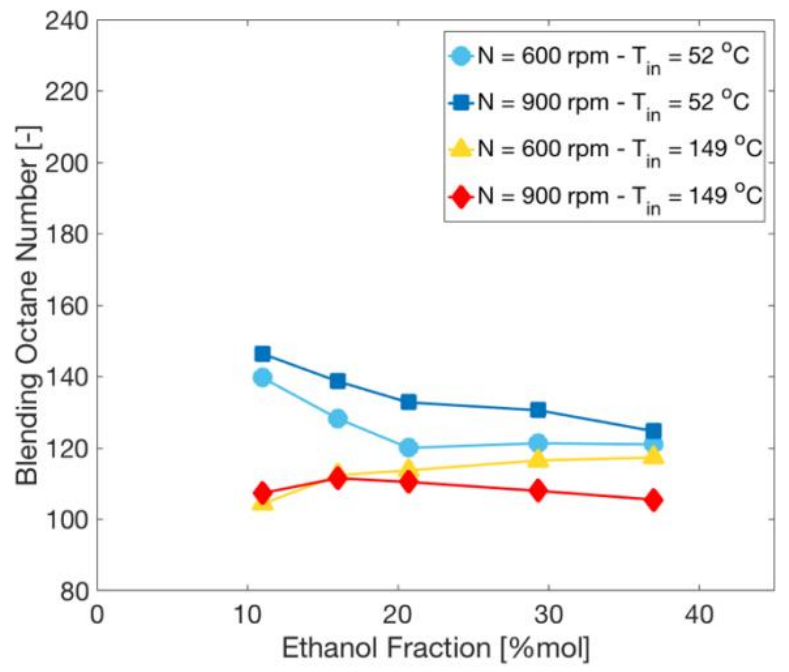

Figure 12. Blending octane number for various molar fraction of ethanol.

\section{Comparing a $\gamma$-valerolactone -ethanol mixture to ethanol}

The preceding sections discussed the octane boosting effects of a GVL-ethanol mixture and pure ethanol in FACE J. In the following section, these results will be compared to evaluate GVL octane boosting potential and discussed accordingly.

\section{Volume-basis approach}

In Figure 13 and 14, the comparisons between the octane boosting effects of a $\gamma$-valerolactone - ethanol mixture and pure ethanol for a given volume fraction of the booster were made for all four set of conditions. For each case, the volumetric fraction of FACE J is kept constant. Figure 13 compares the blending impact of $5 \%$ of $\gamma$ valerolactone $+2.5 \%$ of ethanol by volume and $7.5 \%$ of ethanol by volume blended in $92.5 \%$ of FACE J by volume. Also, the comparison was made for the blending effects of $5 \%$ by volume of either $\gamma$ valerolactone or ethanol in a base fuel comprising of $92.5 \%$ FACE J and $2.5 \%$ ethanol. As can be seen, $\gamma$-valerolactone as octane booster can be nearly as effective as ethanol at the low rotation speed and low intake temperature. For other conditions, ethanol shows greater propensity as octane booster.

Page 8 of 17

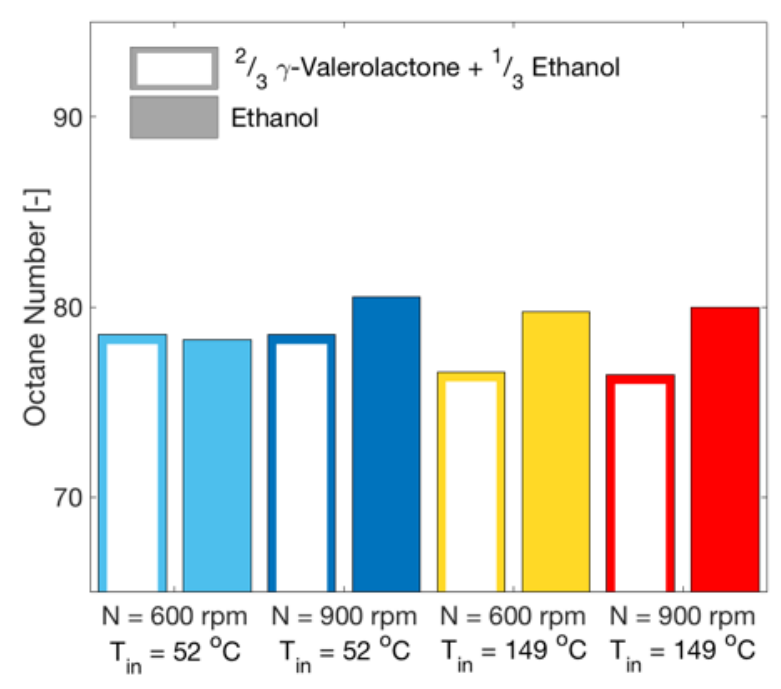

Figure 13. Comparison between a $\gamma$-valerolactone - ethanol mixture and ethanol with a fixed FACE J volumetric fraction of $92.5 \%$.

For higher volume fraction of the booster, $\gamma$-valerolactone and ethanol together is less effective than pure ethanol, and this is found to be true for all HCCI conditions (see Figure 14). These results reveal that $\gamma$ valerolactone is relatively a good octane booster, but it is generally less effective than ethanol.

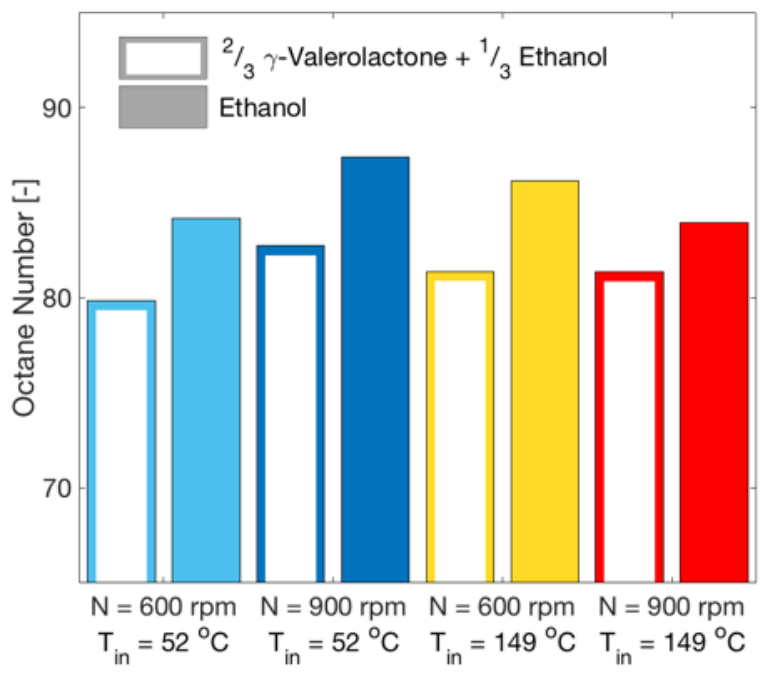

Figure 14. Comparison between a $\gamma$-valerolactone - ethanol mixture and ethanol with a fixed FACE J volumetric fraction of $85 \%$.

\section{Molar-basis approach}

On molar basis, similar comparisons were made in Figure 15 and 16. Here, the comparisons were made for roughly similar, but not identical mole fraction of FACE $J$ in the blends. In the first comparison, the molar fraction of FACE $\mathrm{J}$ was taken as $\sim 88 \%$ which corresponds to the blends of FACE J with $5 \% \gamma$-valerolactone $+2.5 \%$ ethanol or FACE $\mathbf{J}$ with $5 \%$ ethanol. As seen in Figure 15, the molar mixture of $\gamma$-valerolactone + ethanol is found to promote the octane number slightly better as compared to ethanol under the low intake temperature and low rotation speed; whereas the opposite trend is true for high 
intake temperature.

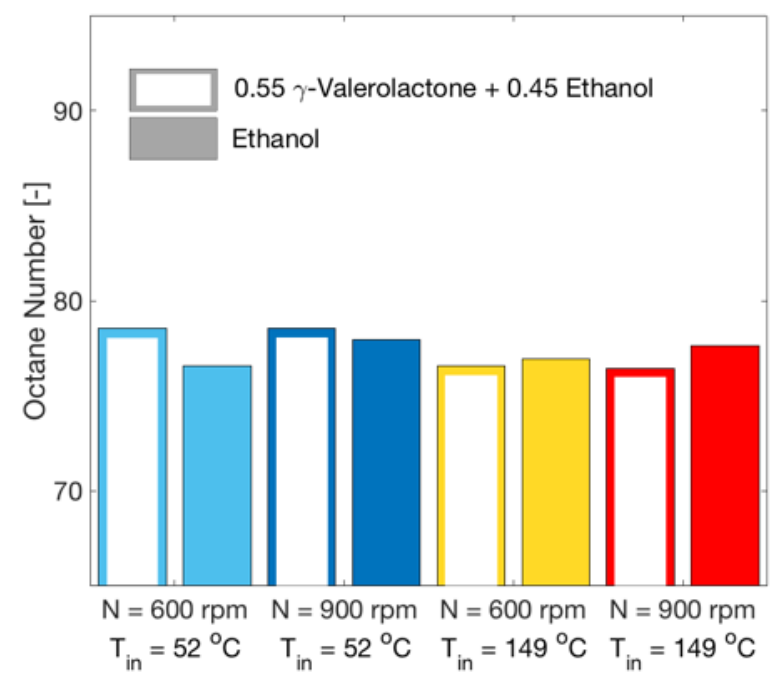

Figure 15. Comparison between a $\gamma$-valerolactone - ethanol mixture and ethanol with a fixed FACE J molar fraction of $88 \%$.

The second comparison is displayed in Figure 16. In this case, the fuel is comprised of $\sim 82 \%$ FACE J by molar fraction, and the rest is made by the mixture of $\gamma$-valerolactone and ethanol. On molar basis, no FACE $\mathbf{J}$ blended with pure ethanol is available for a direct comparison. Nonetheless, this fuel blend is perfectly bracketed in between the two FACE J/ethanol blends comprising of $84 \%$ and $79 \%$ FACE $\mathrm{J}$ by molar fraction. Therefore, a valid comparison can probably be made for these three fuels of comparable molar fraction of FACE J. In volume fraction, these three fuels correspond to $7.5 \% \gamma$-valerolactone $+3.75 \%$ ethanol, $7.5 \%$ ethanol, and $10 \%$ ethanol into FACE J. As can be seen in Figure 16, the presence of $\gamma$-valerolactone has a greater impact under the low intake temperature and low rotation speed only. For other HCCI conditions, its octane enhancement ability is less effective than ethanol. On molar-basis, small fractions of $\gamma$-valerolactone appear to provide greater octane boosting effects, but ethanol blends show more powerful effects than $\gamma$-valerolactone for higher mole fractions under all HCCI conditions.

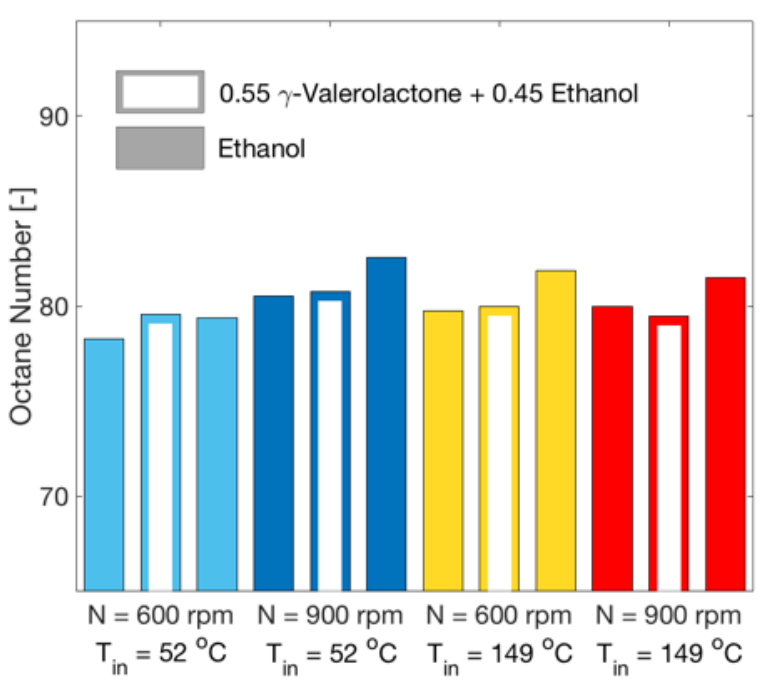

Figure 16. Comparison between a $\gamma$-valerolactone - ethanol mixture and ethanol with roughly $82 \%$ of FACE J by molar fraction.

\section{Blending octane number of $\gamma$-valerolactone}

The selected fuel matrices were not adequate to provide a direct information about the blending octane effects of $\gamma$-valerolactone. Until this point, the non-linear octane boosting effects of two-third $\gamma$ valerolactone and one-third ethanol were reported. The non-linear octane boosting effect of the $\gamma$-valerolactone and ethanol mixture might be largely stemming from ethanol alone. Therefore, an attempt was made to evaluate the blending octane number of $\gamma$-valerolactone through both the volume-basis and the mole-basis approaches.

\section{Volume-basis approach}

According to Equation 1, the blending octane number can be readily computed provided that the rest parameters are known. In the present case, the fuels containing $\gamma$-valerolactone can be used to evaluate the blending octane number of $\gamma$-valerolactone. Here, the octane number of the base fuel is required which can actually be obtained by defining FACE J - ethanol blends as the base fuel. By adopting such an approach, the octane number can be derived from the experimental results presented earlier in section two. Note that there is no unique FACE $\mathrm{J}$ - ethanol base fuel to match with the volume fractions of ethanol and FACE $\mathrm{J}$ in the fuel blends containing $\gamma$-valerolactone. Although the base-fuel is expected to perturb the estimation of the final blending octane number for $\gamma$-valerolactone, the present analysis ignores this fact to at least provide an estimate of the blending octane number of $\gamma$-valerolactone and emphasize non-linear blending effects. The blending octane numbers of $\gamma$-valerolactone were estimated, and the results are presented in Figure 17. 


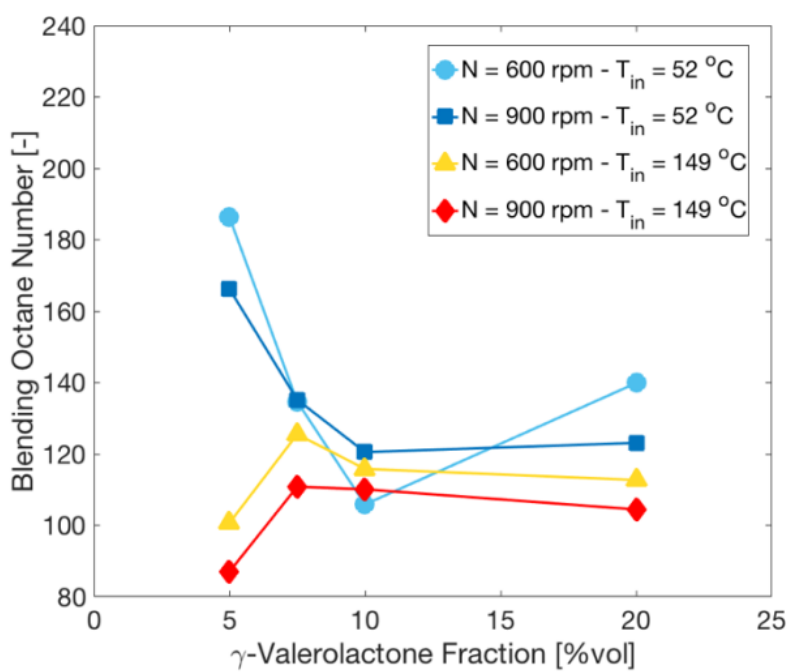

Figure 17. Blending octane number for various volume fraction of $\gamma$ valerolactone.

As can be seen, the blending octane number of $\gamma$-valerolactone ranges between 80 and 200 for the four set of conditions, and they clearly display non-linear octane blending effects. Nonetheless, no more concrete conclusion can be drawn as the base fuel might have some impact on these derived numbers - a different experimental strategy is required to rate the blending octane number of the booster.

\section{Mole-basis approach}

Similarly, the blending octane numbers of $\gamma$-valerolactone were estimated on the molar-basis, and the results are shown in Figure 18.

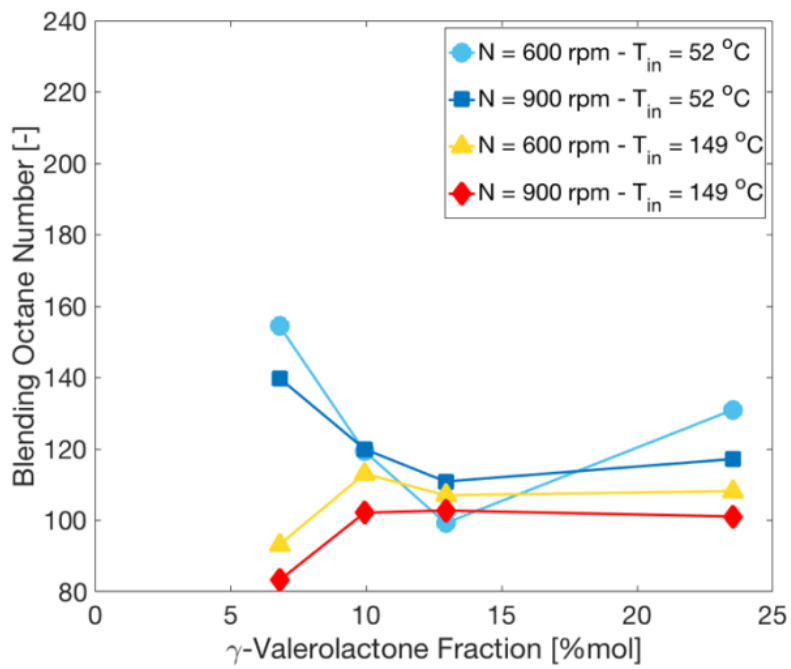

Figure 18. Blending octane number for various mole fraction of $\gamma$ valerolactone.

Similar trends for the blending octane number of $\gamma$-valerolactone were observed for all four HCCI conditions when compared to that of volume basis approach expect that the molar-basis approach compresses the blending octane number to a narrower range between 80 and 160. The results presented in Figure 18 confirm the non-linear

Page 10 of 17 effect of $\gamma$-valerolactone as an octane booster. Yet, the base fuel, whose compositional variation with respect to the fraction of $\gamma$ valerolactone, does not allow to report the final octane number for $\gamma$ valerolactone. Nonetheless, the trends observed with the highest fraction of $\gamma$-valerolactone suggest that this fuel has an octane number somewhere between 100 and 130 .

\section{Conclusions and Perspectives}

This study examined the octane boosting potential of $\gamma$-valerolactone using a CFR engine under four sets of HCCI experimental conditions. As $\gamma$-valerolactone is immiscible with FACE $\mathrm{J}$, ethanol was added as a solvent. Each blend was prepared with a $2 / 3 \gamma$-valerolactone $-1 / 3$ ethanol mixture in FACE $\mathrm{J}$ by volume. In addition, blends of pure ethanol in FACE J were also investigated such that comparison of the results can be made to estimate the boosting effect of pure $\gamma$ valerolactone. The following conclusions are drawn:

- The $\gamma$-valerolactone - ethanol mixture into FACE J resulted into non-linear synergistic and antagonistic octane boosting effects that are found to be dependent on the intake temperature but not on the rotation speed.

- Molar-basis approach showed less pronounced non-linear effects allowing the blending octane number of a fuel or a well-defined mixture for a given condition to be rated easier.

- A direct comparison of the octane number of a $\gamma$ valerolactone - ethanol mixture and pure ethanol reveals that $\gamma$-valerolactone has a stronger octane boosting potential than ethanol for low fractions of $\gamma$-valerolactone. The opposite effect is observed for high fractions of $\gamma$-valerolactone.

- The blending octane number of $\gamma$-valerolactone was estimated, and the results showed that this biofuel provide non-linear octane boosting effects.

This bio-derived molecule looks promising in terms of resistance to the auto-ignition in addition to its known properties for reducing harmful emissions during combustion of hydrocarbon fuels. Moreover, $\gamma$-valerolactone wins over ethanol because of its low vapor pressure and also for its propensity of reducing green-house gases. Because of its extra potential for mitigating harmful emissions, this will be the primary focus of our study in a near future. Also, in future campaign, base fuels with fixed amount of ethanol will be employed for better rating of the blending octane number of $\gamma$-valerolactone.

\section{References}

1. Edenhofer, O., Pichs-Madruga, R., Sokona, Y., Minx, J.C., Farahani, E., Kadner, S., Seyboth, K., Adler, A., Baum, I., Brunner, S., Eickemeier, P., Kriemann, B., Savolainen, J., Schlomer, S., Stechow, C. von, and Zwickel, T., "Climate Change 2014: Mitigation of Climate Change. Chapter 8.," 2014.

2. Berho, F. and Lesclaux, R., "Gas phase reactivity of the cyclohexadienyl radical with $\mathrm{O} 2$ and $\mathrm{NO}$ and thermochemistry of the association reaction with NO," Phys. Chem. Chem. Phys. 3(6):970-979, 2001, doi:10.1039/b009136g.

3. Li, Z., Zeng, X., Tang, X., Sun, Y., and Lin, L., "In-situ prepared nanocopper-catalyzed hydrogenation-liquefaction of biomass in a glycerol-methanol solvent for biofuel 
production," Energy and Fuels 28(7):4273-4281, 2014, doi:10.1021/ef5001375.

4. Azadi, P., Inderwildi, O.R., Farnood, R., and King, D.A., "Liquid fuels, hydrogen and chemicals from lignin: A critical review," Renew. Sustain. Energy Rev. 21:506-523, 2013, doi:10.1016/j.rser.2012.12.022.

5. Bereczky, Á., Lukács, K., Farkas, M., and Dóbé, S., "Effect

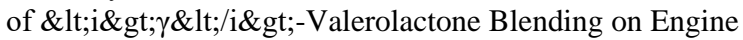
Performance, Combustion Characteristics and Exhaust Emissions in a Diesel Engine," Nat. Resour. 05(05):177191, 2014, doi:10.4236/nr.2014.55017.

6. Horváth, I.T., Mehdi, H., Fábos, V., Boda, L., and Mika, L.T., " $\gamma$-Valerolactone-a sustainable liquid for energy and carbon-based chemicals," Green Chem. 10(2):238-242, 2008, doi:10.1039/b712863k.

7. Simmie, J.M., Bruycker, R. De, Geem, K.M. Van, Marin, G.B., Reyniers, M.-F., and Carstensen, H.-H., "An experimental and kinetic modeling study of $\gamma$-valerolactone pyrolysis," Combust. Flame 164:183-200, 2015, doi:10.1016/j.combustflame.2015.11.016.

8. Alonso, D.M., Wettstein, S.G., and Dumesic, J.A., "Gammavalerolactone, a sustainable platform molecule derived from lignocellulosic biomass," Green Chem. 15(3):584-595, 2013, doi:10.1039/c3gc37065h.

9. Tang, X., Zeng, X., Li, Z., Hu, L., Sun, Y., Liu, S., Lei, T., and Lin, L., "Production of $\gamma$-valerolactone from lignocellulosic biomass for sustainable fuels and chemicals supply," Renew. Sustain. Energy Rev. 40:608-620, 2014, doi:10.1016/j.rser.2014.07.209.

10. Yan, K., Yang, Y., Chai, J., and Lu, Y., "Catalytic reactions of gamma-valerolactone: A platform to fuels and valueadded chemicals," Appl. Catal. B Environ. 179:292-304, 2015, doi:10.1016/j.apcatb.2015.04.030.

11. Kalghatgi, G.T., "Developments in internal combustion engines and implications for combustion science and future transport fuels," Proc. Combust. Inst. 35(1):101-115, 2015, doi:10.1016/j.proci.2014.10.002.

12. Masurier, J.-B., Elkhazraji, A., Mohammed, A., and Johansson, B., "HCCI Octane Number Scale in a PressureTemperature Diagram," SAE Tech. Pap., 2019, doi:10.4271/2019-01-0965.

13. Javed, T., Ahmed, A., Lovisotto, L., Issayev, G., Badra, J., Sarathy, S.M., and Farooq, A., "Ignition studies of two lowoctane gasolines," Combust. Flame 185:152-159, 2017, doi:10.1016/j.combustflame.2017.07.006.

14. Kovacs, L., Csupor, D., Lente, G., and Gunda, T., "100 Chemical Myths - Misconceptions, Misundrstandings, Explanations," 2014, doi:doi.org/10.1007/978-3-319-084190 .

15. Yan, J., Shamim, T., Chou, S.K., Desideri, U., and Li, H., "Clean, efficient and affordable energy for a sustainable

Page 11 of 17 future," Appl. Energy 185:In Press, 2016, doi:10.1016/j.apenergy.2016.06.005.

16. Aroonsrisopon, T., Foster, D., Morikawa, T., and Lida, M., "Comparison of HCCI Operating Ranges for Combinations of Intake Temperature , Engine Speed and Fuel Composition," SAE Tech. Pap. (2002-01-1924), 2002, doi:10.4271/2002-01-1924.

17. Dubreuil, A., Foucher, F., and Mounaïm-Rousselle, C., "Effect of EGR Chemical Components and Intake Temperature on HCCI Combustion Development," SAE Tech. Pap. 32(0044), 2006, doi:10.4271/2006-32-0044.

18. Waqas, M., Naser, N., Sarathy, M., Morganti, K., AlQurashi, K., and Johansson, B., "Blending Octane Number of Ethanol in HCCI , SI and CI Combustion Modes," SAE Int. J. Fuels Lubr. 9(3), 2016, doi:10.4271/2016-01-2298.

19. Anderson, J.E., Kramer, U., Mueller, S.A., and Wallington, T.J., "Octane numbers of ethanol- and methanol-gasoline blends estimated from molar concentrations," Energy and Fuels 24(12):6576-6585, 2010, doi:10.1021/ef101125c.

20. Morgan, N., Smallbone, A., Bhave, A., Kraft, M., Cracknell, R., and Kalghatgi, G., "Mapping surrogate gasoline compositions into RON / MON space," Combust. Flame 157(6):1122-1131, 2010, doi:10.1016/j.combustflame.2010.02.003.

21. Anderson, J.E., Leone, T.G., Shelby, M.H., Wallington, T.J., Bizub, J.J., Foster, M., and Lynskey, M.G., "Octane Numbers of Ethanol-Gasoline Blends: Measurements and Novel Estimation Method from Molar Composition," SAE Int. 01(1274), 2012, doi:10.4271/2012-01-1274.

22. Foong, T.M., Morganti, K.J., Brear, M.J., Silva, G. Da, Yang, Y., and Dryer, F.L., "The octane numbers of ethanol blended with gasoline and its surrogates," Fuel 115:727739, 2014, doi:10.1016/j.fuel.2013.07.105.

23. Wang, C., Zeraati-Rezaei, S., Xiang, L., and Xu, H., "Ethanol blends in spark ignition engines: RON, octaneadded value, cooling effect, compression ratio, and potential engine efficiency gain," Appl. Energy 191:603-619, 2017, doi:10.1016/j.apenergy.2017.01.081.

24. Pera, C. and Knop, V., "Methodology to define gasoline surrogates dedicated to auto-ignition in engines," Fuel 96:59-69, 2012, doi:10.1016/j.fuel.2012.01.008.

\section{Contact Information}

Jean-Baptiste Masurier

jeanbaptiste.masurier@kaust.edu.sa

Binod R. Giri

binod.giri@kaust.edu.sa 


\section{Acknowledgments}

Research reported in this publication was funded by the Office of Sponsored Research at King Abdullah University of Science and Technology (KAUST).

The research reported in this publication was supported by funding from King Abdullah University of Science and Technology (KAUST).

The authors also thank Adrian I. Ichim and Riyad H. Jambi for their technical support.

\section{Definitions/Abbreviations}

$\begin{array}{ll}\text { \% mol } & \text { Mole fraction } \\ \text { \% vol } & \text { Volume fraction } \\ { }^{\circ} \text { C } & \text { Celsius degree } \\ \text { CA } & \text { Crank Angle } \\ \text { CFR } & \text { Cooperative Fuel Research } \\ \text { EtOH } & \text { Ethanol } \\ \text { FACE } & \text { Fuel for Advanced } \\ & \text { Combustion Engine } \\ \text { GVL } & \gamma \text {-valerolactone }\end{array}$

HCCI

LTHS

Homogeneous Charge Compression Ignition

HTHS

High Temperature High Speed

HTLS

High Temperature Low Speed

ICE

Internal combustion engine

LA

Levullinic acid

Low Temperature High Speed

LTLS

PRF

Low Temperature Low Speed

Primary Reference Fuel

rpm

Rotation per minute 
Appendix 1 - Results for Primary Reference Fuels
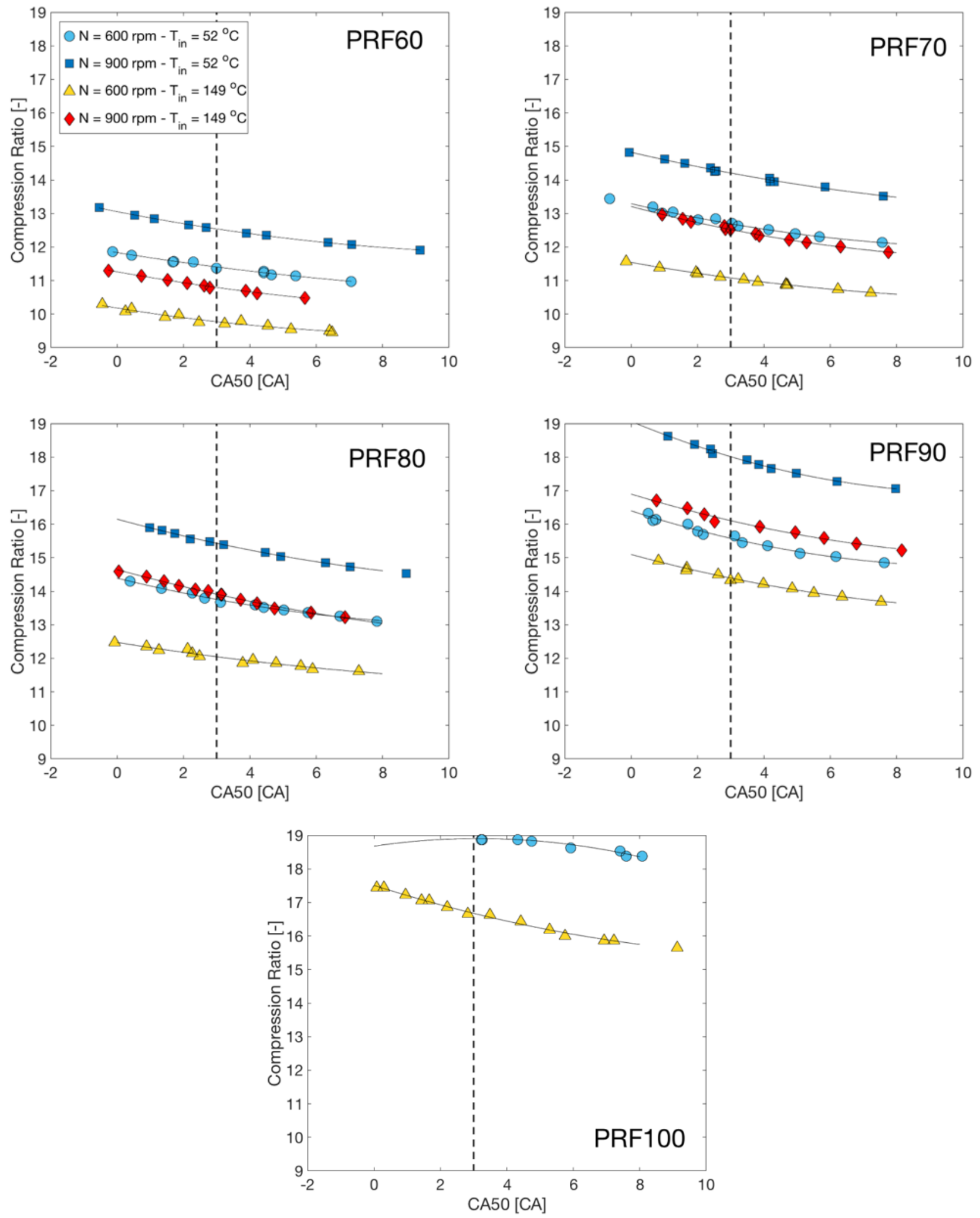

Figure Appendix 1. Results from PRF60 to PRF100.

Page 13 of 17

$10 / 19 / 2016$ 


\begin{tabular}{cccc}
\hline \hline Conditions & Second-degree coefficients & First-degree coefficients & Zero-degree coefficients \\
\hline \hline LTLS & -0.5728 & 22.7525 & -125.3949 \\
LTHS & -0.4039 & 17.9402 & -101.8954 \\
HTLS & -0.4599 & 17.8778 & -70.6653 \\
HTHS & -0.2198 & 11.6542 & -40.4854 \\
\hline \hline
\end{tabular}

Page 14 of 17

10/19/2016 
Appendix 2 - Results for FACE J

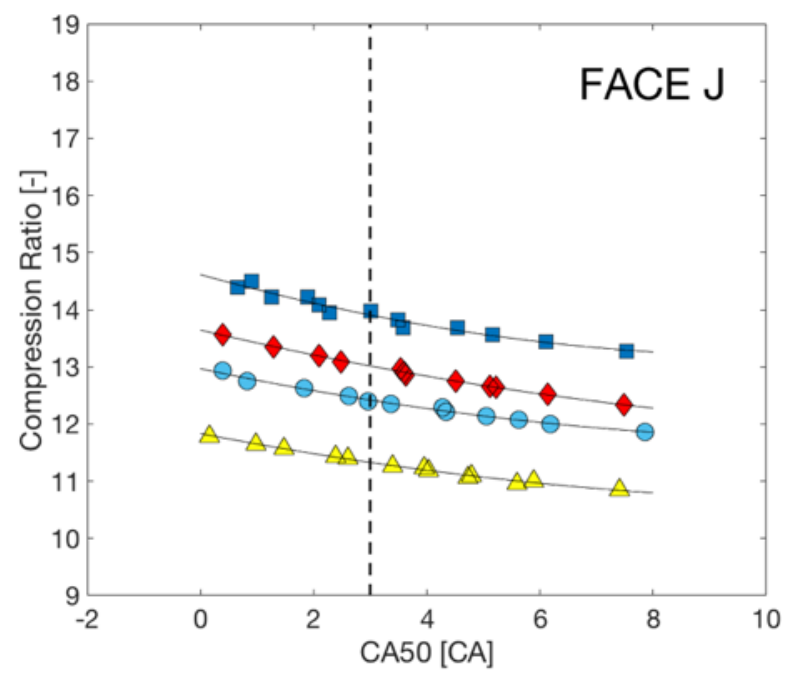

Figure Appendix 2. Results for FACE J as fuel.

Page 15 of 17

10/19/2016 
Appendix 3 - Results for FACE J with Ethanol and GVL
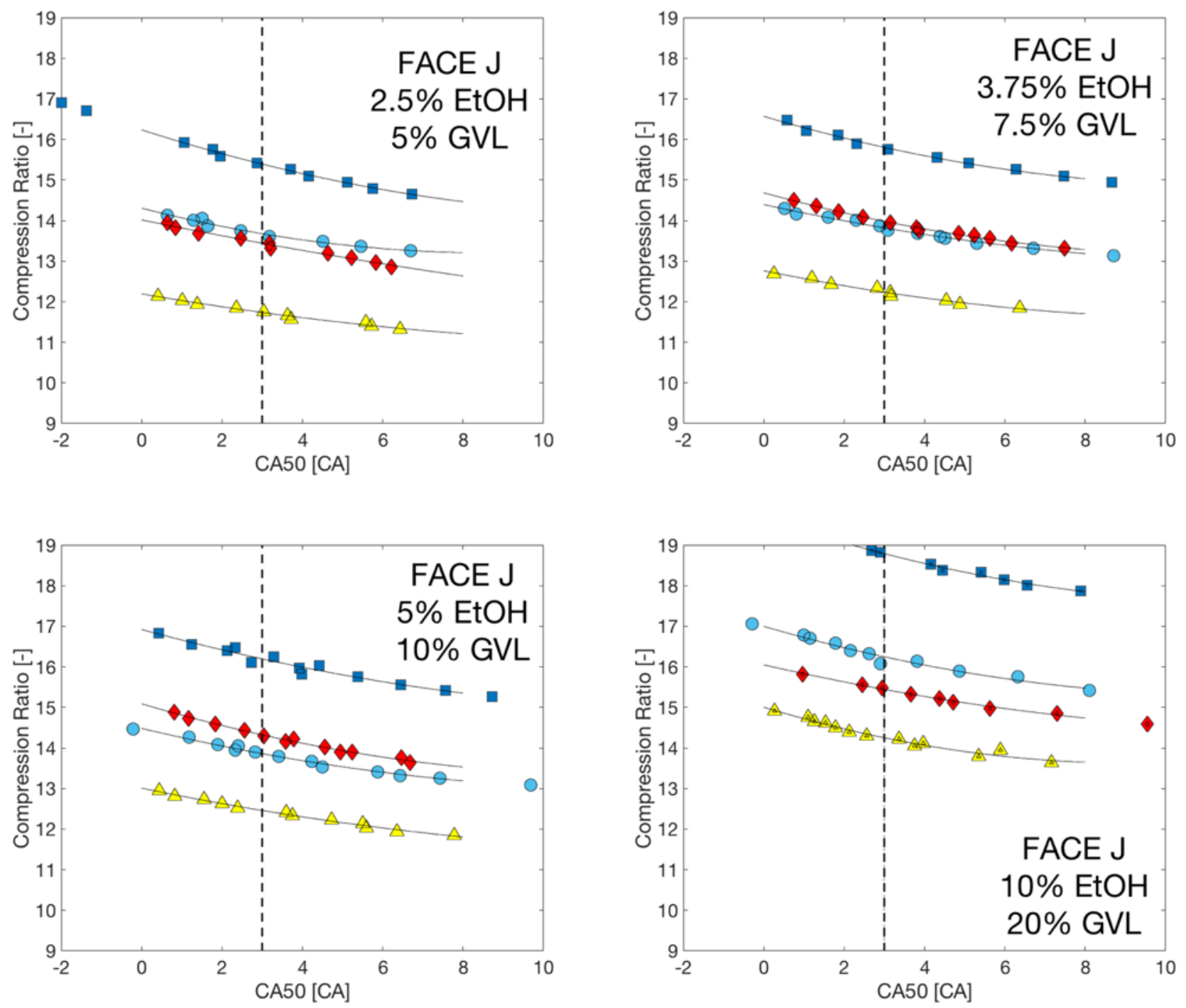

Figure Appendix 3. Results for FACE J blended with ethanol and $\gamma$-valerolactone. 


\section{Appendix 4 - Results for FACE J with Ethanol only}
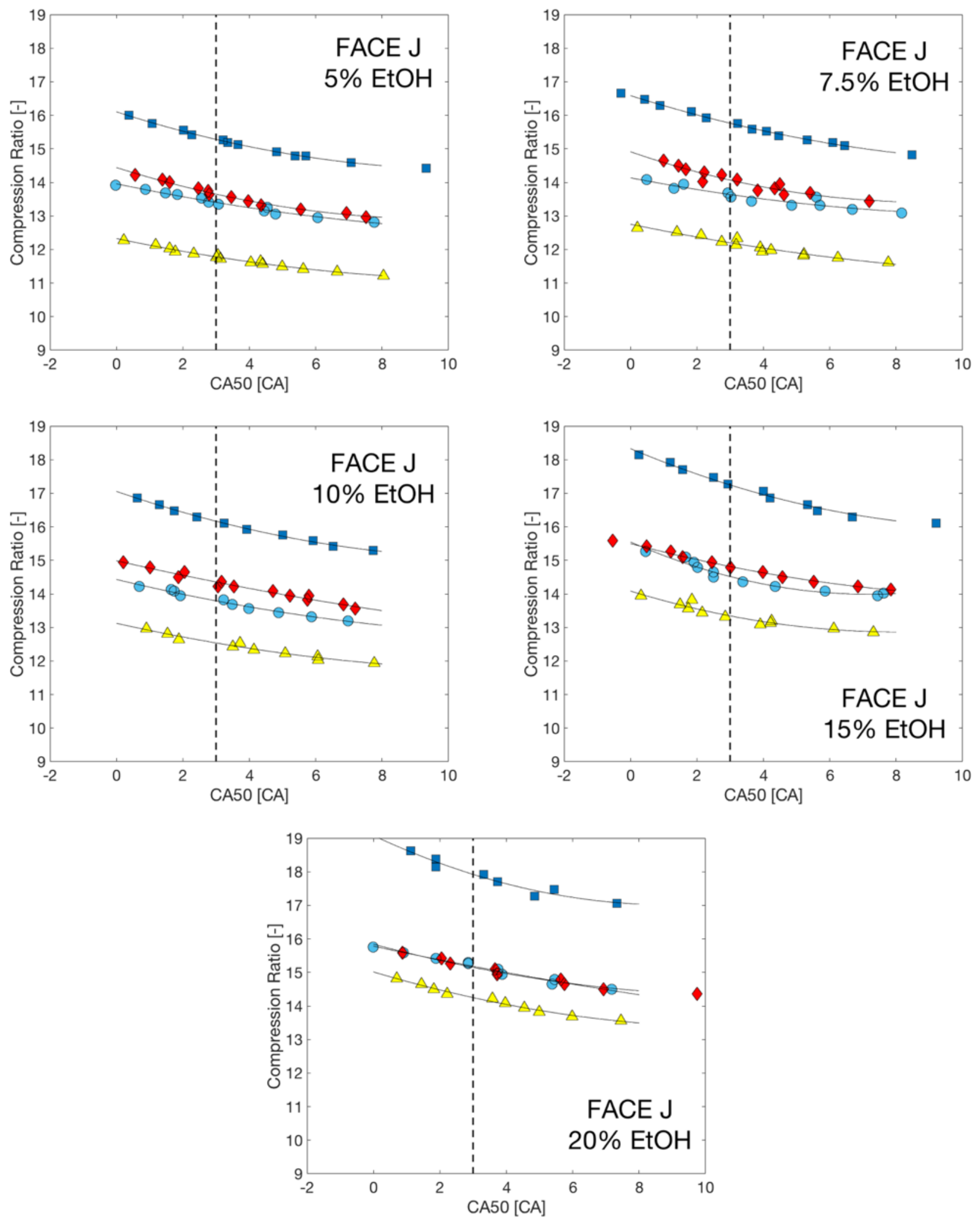

Figure Appendix 4. Results for FACE J blended with ethanol.

Page 17 of 17

$10 / 19 / 2016$ 